\title{
A WIN-WIN SOLUTION FOR MUTUAL BENEFIT AND PROSPERITY
}

Dear Reader,

Nobel Laureate Prof. Amartya Sen cites a story of three children, Anne, Bob and Carla. Prof. Sen quotes Aristotle and Bentham too while narrating the story, I heard from Prof (Dr.) James Nedumpara at his recent live lecture at Jindal Global Law School. This story fascinated me and it goes like this. Clara worked hard to successfully build a flute. Anne knows to play the flute, but Clara does not know to play the flute. Bob, the third child, does NOT have any toys to play with, so he wants

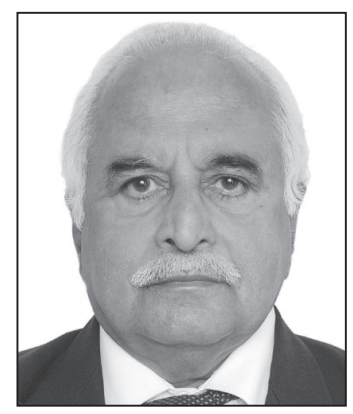
the flute. All the children are claimants to the flute. Prof. Sen and many legal luminaries quote many legal theories such as Libertarianism, Utilitarianism, Egalitarian and also try to distinguish between "Niti and Nyaya" to resolve this problem, as to who merits (deserts and deserve) to keep the flute. The debate and deliberations go on and pens go dry, of the reviewers, commentators and lecturers in UPSC and higher legal studies. Here is where and when it dawned on me that I have the right formula to resolve this dispute or dilemma. I draw on my little bit of experience in Intellectual Property, especially Patents and pharmaceutical industry to extend this story and find a resolution. Let me replant these characters into my story as follows;

Extended to Industry scenario, Carla is a Research Scientist in Academic or Research Institute, who has come up with a breakthrough innovation which has high potential to be utilised or commercialised. She patents the invention. However, she does not have a manufacturing facility and does not know how to scale up to commercial levels. Bob has manufacturing facility but does not have the finances or working capital as well as technically qualified professionals to scale up Carla's invention and take it to the market place. Anne is an experienced pharmacist with extra-ordinary expertise in scaling-up and making the product and taking it to the market as a block-buster. Once Anne, Bob and Carla come under the venture-based start-up umbrella, the dispute is resolved. Carla licenses it to Anne who gets it manufactured with Bob. All are happy in a win-win end of the story.

The Indian Pharmaceutical Industry is already on a win-win route, having commenced working on this model of partnerships. Research institutes and Universities such as ICT (Institute of Chemical Technology, Mumbai), Indian Institute of Chemical Technology (IICT), Hyderabad, IITs and their innovation hubs, NCL (National Chemical Laboratory, Pune) and their Venture Center, renowned universities and colleges such as JSS Ooty/Mysuru, SRM, Amity, Manipal, Punjab, Andhra and others. It is heartening to note that more and more Corporates are working closely with research entities in Academic environs. The breakthroughs achieved by CIPLA by working with CSIR Laboratories such as NCL (Pune); CDRI, Lucknow; IIM (Indian Institute of Integrative Medicine), Jammu and others are being replicated by many leading pharmaceutical and biological corporate leaders Biocon, Zydus, Alembic, Aurobindo, FDC, Mankind and many more. In this context, I am happy to recall the Guest Editorial by Dr. Madhu Dikshit in the April, 2019 issue of Indian Drugs. There is a huge data bank of research professional who have retired from active and vibrant centres in public research laboratories, who can be productively made 
to associate with public-private research initiatives. Indian Drugs and IDMA will be happy to contribute in an organized platform for making such tie-ups and alliances fruitful and innovatively successful.

It is heartening to note that the Government of India is fully aware of the potential role and contribution from educational institutions and universities which are valuable in generation of new technologies and patentable innovations. Keeping this aspect in mind, Department for Promotion of Industry and Internal Trade under Ministry of Commerce has come out with a Patents (Amendment) Rules, 2021 extending the $80 \%$ reduction in patent filing and prosecution fees to all recognized educational institutions (whether or not financed or owned or controlled by the Government) along with Natural person, Start-up and Small entities.

Much more needs to be done and achieved. Instead of having success stories to quote, it should become a day-to-day habit and routine for all of industry including MSME to partner with academic, researchers and industry professionals. There are no dearth of mentors and gurus. They need to be approachable to make them part of the projects and make the deals and tie-ups, part of supply chain management. Every organization, research industry or consultancies and professional must get interconnected and be ready to take off, anytime and every time. Let us make it happen, the winwin-win story of Anne, Bob and Carla.

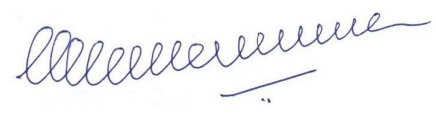

Dr. Gopakumar G. Nair

Editor

Indian Drugs

https://doi.org/10.53879/id.58.07.p0005

\section{About The Editor}

Dr. Gopakumar G. Nair is a Ph.D in Organic Chemistry (1966) from National Chemical Laboratory, Pune (Pune University). He was a Post-Doctoral fellow at IIT Bombay, Powai (1967) before joining the Pharma Industry. He was Director of Bombay Drug House P. Ltd., later Chairman of BDH Industries Ltd. as well as CMD of Bombay Drugs \& Pharma Ltd., which was merged with Strides Arcolab Ltd. in 2001. Dr. Nair served IDMA as office bearer for many years from 1972 onwards and was Chairman of various Committees for nearly 4 decades. He was the President of IDMA in 1999/2000. Currently, Dr. Nair is the Chairman of the IPR Committee in IDMA.

Having moved into the Intellectual Property field, he was the Dean of IIPS (Institute of Intellectual Property Studies) at Hyderabad in 2001/2002. Later, he set up his own boutique IP firm, Gopakumar Nair Associates, as well as Gnanlex Hermeneutics Pvt. Ltd., having done his L. L. B. from Mumbai University. He is also CEO of Patent Gurukul and President of Bharat Education Society, Kurla, Mumbai, managing many educational institutions in and around Mumbai.

五

If you would like to comment on the editorial please write to us at publications@idmaindia.com 